\title{
Estimativa/2020 - Incidência de Câncer no Brasil
}

https://doi.org/10.32635/2176-9745.RBC.2020v66n1.927

\section{Estimate/2020 - Cancer Incidence in Brazil \\ Estimación/2020 - Incidencia de Cáncer em Brasil}

\section{Marceli de Oliveira Santos ${ }^{1}$}

Os Registros de Câncer de Base Populacional $(\mathrm{RCBP})^{1}$ são o padrão-ouro para conhecer a incidência de câncer e, portanto, o melhor instrumento para o monitoramento e a avaliação das açôes de vigilância. O Ministério da Saúde, com base na existência de um amplo conjunto de experiências em desenvolvimento no Brasil desde a década de 1960, apoiou as ações para a implantação de centros de informação que coletassem, processassem e divulgassem informaçôes sobre câncer. Assim, surgiram os primeiros Registros de Câncer no Brasil ${ }^{2}$, de diversas naturezas, com o objetivo de evidenciar a magnitude dessa doença e fornecer indicadores que pudessem ser utilizados para o estabelecimento de diretrizes para prevenção e controle do câncer.

Nos últimos 35 anos, o Instituto Nacional de Câncer José Alencar Gomes da Silva (INCA) tem apoiado a implantação e a manutenção dos Registros de Câncer no Brasil, promovendo ações de natureza técnica que visam à padronização e à qualificação das informações, bem como à capacitação técnica dos profissionais que trabalham nessa área. Ao longo desse tempo, houve uma clara evolução dos RCBP no Brasil, além de aumentarem em quantidade. Na década de 1980, havia um em cada Região do país e atualmente existe pelo menos um em cada Estado do Brasil. Os RCBP têm melhorado a qualidade da informação e constituído séries históricas, fundamentais para o monitoramento. Dos 28 RCBP com informação disponível, apenas dois possuem menos de cinco anos de informação consolidada.

Com a disponibilidade de informaçóes fidedignas e abundantes, foi possível a incorporação de modelos mais sofisticados para a elaboração da nova estimativa de incidência de câncer. A estimativa de câncer elaborada pelo INCA está alinhada com a metodologia utilizada pela Agência Internacional para Pesquisa em Câncer ${ }^{4}$ (do inglês, International Agency for Research on Cancer - Iarc) para a elaboração das estimativas mundiais (Globocan) ${ }^{3}$, que compóe o Observatório Global de Câncer.

A estimativa de casos novos de câncer é elaborada para o Brasil e desagregada por Região geográfica, Estados, capitais e o Distrito Federal. Esse formato, único na América Latina e Caribe, conferiu ao nosso país o reconhecimento de que este se situa entre os que mais têm avançado na consolidação de um sistema integrado de vigilância de câncer.

Ainda existem muitos desafios, entre eles, a estratégia de manter e fortalecer os centros de informação (Registros de Câncer de Base Populacional e Hospitalares) de tal forma que permitam monitorar a situação do câncer como parâmetro para todo o país; e, nessa lógica, por meio das estimativas de câncer, oferecer informaçóes atualizadas e aplicáveis às necessidades estratégicas do país.

\section{REFERÊNCIAS}

1. Instituto Nacional de Câncer. Câncer no Brasil: dados dos registros de câncer de base populacional. vol. 3. Rio de Janeiro: INCA; 2003.

2. Instituto Nacional de Câncer José Alencar Gomes da Silva [Internet]. Rio de Janeiro: INCA; c1996-2018. [acesso 2020 fev. 19]. Registro de câncer de base populacional. Disponível em: https://www.inca.gov.br/app/incidencia-basepop

3. International Agency for Research on Cancer [Internet]. France: IARC; [cited 2020 Feb 19]. National Cancer Institute (Instituto Nacional de Câncer). Available from: https://gicr.iarc.fr/training-center/brazil-iarc-gicr-collaborating-centre/

4. Ferlay J, Colombet M, Soerjomataram I, et al. Estimating the global cancer incidence and mortality in 2018: GLOBOCAN sources and methods. Int J Cancer. 2019;144(8):1941-53. doi: https://doi.org/10.1002/ijc.31937 